HEART

\title{
Effects of stem cell therapy with G-CSF on coronary artery after drug-eluting stent implantation in patients with acute myocardial infarction
}

H-J Kang, Y-S Kim, B-K Koo, K W Park, H-Y Lee, D-W Sohn, B-H Oh, Y-B Park and $\mathrm{H}$-S Kim

Heart 2008;94;604-609; originally published online 10 Dec 2007;

doi:10.1136/hrt.2007.128348

Updated information and services can be found at:

http://heart.bmj.com/cgi/content/full/94/5/604

These include:

Data supplement "web only appendices"

http://heart.bmj.com/cgi/content/full/94/5/604/DC1

References This article cites 18 articles, 12 of which can be accessed free at:

http://heart.bmj.com/cgi/content/full/94/5/604\#BIBL

2 online articles that cite this article can be accessed at:

http://heart.bmj.com/cgi/content/full/94/5/604\#otherarticles

Rapid responses You can respond to this article at:

http://heart.bmj.com/cgi/eletter-submit/94/5/604

Email alerting Receive free email alerts when new articles cite this article - sign up in the box at service the top right corner of the article

Topic collections Articles on similar topics can be found in the following collections

Drugs: cardiovascular system (9992 articles)

Interventional cardiology (3181 articles)

Acute coronary syndromes (1276 articles)

Clinical diagnostic tests (9110 articles)

Notes

To order reprints of this article go to:

http://journals.bmj.com/cgi/reprintform

To subscribe to Heart go to:

http://journals.bmj.com/subscriptions/ 


\title{
Effects of stem cell therapy with G-CSF on coronary artery after drug-eluting stent implantation in patients with acute myocardial infarction
}

\author{
H-J Kang, ${ }^{1}$ Y-S Kim, ${ }^{2}$ B-K Koo, ${ }^{1}$ K W Park, ${ }^{1}$ H-Y Lee, ${ }^{1}$ D-W Sohn, ${ }^{1}$ B-H Oh, ${ }^{1}$ Y-B Park, ${ }^{1}$ \\ $\mathrm{H}-\mathrm{S} \mathrm{Kim}{ }^{3}$
}

- Additional figures and articles are published online only at http://heart.bmj.com/content/ vol94/issue5

${ }^{1}$ Innovative Research Institute for Cell Therapy/Cardiovascular Center, Seoul National University Hospital, Seoul, Korea;

${ }^{2}$ Department of Internal Medicine, DongGuk University International Hospital, Ilsan,

Korea; ${ }^{3}$ National Research Laboratory for Cardiovascular

Stem Cell, Seoul National University, Seoul, Korea

Correspondence to: Dr Hyo-Soo Kim, Dr Young-Bae Park, Department of Internal Medicine, Seoul National University Hospital, 28 Yongondong, Chongno-gu, Seoul 110744, Republic of Korea: hyosoo@snu.ac.kr

H-JK and YSK contributed equally to this study

Accepted 27 November 2007 Published Online First 10 December 2007

\section{ABSTRACT}

Objective: The effects of stem cell therapy on the coronary vasculature were investigated in patients with acute myocardial infarction who underwent peripheral blood stem cell (PBSC) therapy in the MAGIC Cell-3-DES study.

Methods: Among 50 patients with acute myocardial infarction who underwent either sirolimus-eluting stent or paclitaxel-eluting stent implantation for the culprit lesion, intravascular ultrasound was analysed in 36 patients (cell infusion: $n=19$ and control: $n=17)$. In the cell infusion group, PBSCs mobilised by granulocyte-colony stimulating factor were delivered via intracoronary infusion into infarcted myocardium. Proximal and distal reference segments, and stented segments, were evaluated with intravascular ultrasound at immediate post-intervention and 6-month follow-up, respectively.

Results: In the proximal and distal reference segments, the serial changes of lumen area, vessel area, and plaque plus media area were not significantly different between the cell infusion and the control groups. Within stented segments, mean neointimal area was similar in the two groups (cell infusion: 0.2 (SD 0.5) $\mathrm{mm}^{2}$ vs control: 0.3 (SD $\left.0.4) \mathrm{mm}^{2}, \mathrm{p}>0.05\right)$. However, there was a significant increase in mean peri-stent area of stented segment in the cell infusion group compared with the control group (0.7 (SD 1.4) $\mathrm{mm}^{2}$ vs -0.1 (SD 1.2) $\mathrm{mm}^{2}, \mathrm{p}<0.05$ ). This difference mainly came from paclitaxel-eluting stentimplanted patients.

Conclusion: Intracoronary infusion of PBSCs mobilised with G-CSF does not aggravate de novo atherosclerotic lesion and neointimal hyperplasia with DES implantation. However, it may induce peri-stent tissue growth at the stented segment, especially in patients receiving PES. Its clinical significance needs to be evaluated with long-term follow-up.

Recent clinical trials have shown favourable effects of bone marrow-derived stem cell therapy on left ventricular function and remodelling after myocardial infarction. ${ }^{1-4}$ However, the possibility that stem cell therapy might aggravate de novo atherosclerosis or restenosis has also been suggested and regarded as a potential limitation of stem cell therapy. ${ }^{3-6}$ Recently, we reported the results of the Myocardial Regeneration and Angiogenesis in Myocardial Infarction with G-CSF and Intracoronary Stem Cell Infusion-3-Drug eluting stent trial (MAGIC Cell-3-DES trial), which showed a favourable effect of intracoronary infusion of peripheral blood stem cells (PBSCs) mobilised by granulocyte colony-stimulating factor
(G-CSF) with drug-eluting stent (DES) implantation on left ventricular systolic function and remodelling in patients with acute myocardial infarction (AMI) without any risk for restenosis based on angiographic data. ${ }^{7}$ However, the effects of intracoronary infusion of stem cells on the coronary vasculature, including neointimal growth and vascular remodelling within stented segments or de novo atherosclerotic lesions, are mostly unknown. The aim of this study was to evaluate the effect of infusion of PBSCs mobilised by G-CSF on segments stented with DES and segments without intervention using serial quantitative intravascular ultrasound (IVUS) analyses.

\section{METHODS}

\section{Patient selection}

The MAGIC Cell-3-DES trial was a randomised, controlled trial to recruit 50 patients with acute and 36 patients with old myocardial infarction, respectively. In this study, AMI was defined as randomisation within 14 days from onset of new ST-segment elevation myocardial infarction. Eligible for enrolment were patients who were successfully revascularised at the culprit lesion with the use of either sirolimus-eluting stents (SES; Cypher, Cordis, Miami Lakes, FL) or paclitaxel-eluting stents (PES; TAXUS, Boston Scientific Corporation, Boston, MA). The current IVUS study included only patients with AMI who underwent serial IVUS examination at post-intervention and 6-month follow-up and whose IVUS data were adequate for analysis. The study protocol was approved by the Institutional Review Board of Seoul National University Hospital. Informed written consent was obtained from all patients after the procedure and risk of the study had been explained.

\section{Stem cell mobilisation, characterisation and intracoronary infusion}

In the cell infusion groups after successful stent implantation, PBSCs were mobilised from bone marrow by G-CSF (Dong-A Pharmaceutical, Seoul, Korea) at $10 \mu \mathrm{g} / \mathrm{kg}$ body weight for 3 days. On day 4, mobilised PBSCs were collected with COBE spectra apheresis system (COBE BCT Inc., Lakewood, CO, USA) using the mononuclear cell collection method. The infusion cell doses were $1-$ $2 \times 10^{9}$ mononuclear cells per patient to guarantee the minimum target cell dose of $7 \times 10^{6} \mathrm{CD} 34+$ cells. We infused PBSCs selectively into infarcted 
myocardium via over-the-wire balloon catheter as previously described. ${ }^{3}$ Placebo was not applied to the control group.

\section{Quantitative angiographic analysis}

Coronary angiograms were obtained at baseline and 6-month follow-up. Quantitative coronary angiographic analysis (OCA) was performed by an independent blinded specialist with Quantcor OCA V4.0 program (Pie medical imaging, The Netherlands).

\section{Intravascular ultrasound imaging}

Serial IVUS examinations at post-intervention and 6-month follow-up were performed in an identical fashion using a commercially available system (ClearView or Galaxy2, Boston Scientific Corporation, USA). Before insertion of the IVUS catheter, nitroglycerin 100-200 $\mu \mathrm{g}$ was injected into the coronary artery. The catheter was advanced at least $10 \mathrm{~mm}$ beyond the stented segment, and imaging was performed from there to the aorto-ostial junction. The transducer was withdrawn automatically at a speed of $0.5 \mathrm{~mm} / \mathrm{s}$. All IVUS images were recorded on VHS videotape and digitalised for off-line analysis.

\section{Intravascular ultrasound analysis}

IVUS images were analysed by a single experienced operator, blinded to patients' information, using the EchoPlaque 2.7 (INDEC Systems Inc., Mountain View, CA). The leading edges of the lumen, stent and external elastic membrane (EEM) borders were traced by manual planimetry. We performed quantitative analysis in the stented segment and the proximal and distal reference segments, which were defined as 5 -mm vessel segments proximal and distal to the stents. If the EEM could not be detected due to heavy calcification with acoustic shadowing or side branches located within the 5 -mm segment proximal or distal to the stent, that segment was excluded from analysis. Cross-sectional area of the lumen, the stent, and EEM were measured in steps of $1 \mathrm{~mm}$, and mean values of each parameter in each segment were regarded as mean lumen area (LA), mean stent area (SA), and mean vessel area (VA), respectively. Mean plaque plus media area (PMA) in the proximal and distal reference segments was derived by VA LA, and mean neointimal area (NIA) and mean peri-stent area (PSA) in the stented segment were derived by SA - LA and VA - SA, respectively.

\section{Statistical analysis}

Categorical variables are given as percentages and were tested with Fisher's exact test. Continuous variables are presented as mean (SD). Area changes ( $\Delta$ values) for each measurement were calculated as follow-up minus post-intervention value. Comparisons between post-intervention and 6-month followup values were performed using the Wilcoxon signed rank test, whereas comparison between two groups was performed using the Mann-Whitney $U$ test. A value of $p<0.05$ was considered statistically significant. Statistical analysis was performed using the SPSS program (version 12.0, SPSS Inc., Chicago, IL).

\section{RESULTS}

\section{Study population and baseline characteristics}

In the MAGIC Cell-3-DES trial, 50 patients with AMI completed 6-month follow-up. Among these patients, we completed evaluation in 36 patients who had analysable postintervention baseline and 6-month follow-up IVUS data for the present study (control: $n=17$, cell infusion: $n=19$ ). Serial IVUS was available for the stented segment in 17 control and 19 cell infusion patients, for the proximal reference segment in nine control and 14 cell infusion patients, and for the distal reference segment in 14 control and 16 cell infusion patients, respectively. In the proximal reference segments, 13 segments were not analysable due to ostial lesion $(n=8)$, heavy calcification $(n=2)$ or presence of side branches $(n=3)$. In the distal reference segments, six segments were not analysable due to heavy calcification $(n=2)$ or presence of side branches $(n=4)$. Only two patients in the control group experienced angiographic binary restenosis at 6-month follow-up, and one patient was included in the IVUS study.

The baseline characteristics of the patients and pharmacological treatment during the follow-up period are shown in table 1. There were no significant differences in the baseline characteristics between the two groups except for the low density lipoprotein cholesterol (LDL) level. The baseline procedural parameters and quantitative angiographic data are summarised in table 1. Procedural parameters were similar in the two groups. As measured by OCA, there were no significant differences in

Table 1 Baseline characteristics of patients

\begin{tabular}{|c|c|c|c|}
\hline & Control & Cell infusion & p Va \\
\hline \multicolumn{4}{|l|}{ Clinical and laboratory data } \\
\hline No. of patients & 17 & 19 & \\
\hline Age (years) & $56.0(13.4)$ & $57.0(13.5)$ & 0.83 \\
\hline Male & $14(82 \%)$ & $16(84 \%)$ & 1.00 \\
\hline Current smoker & $8(47 \%)$ & $9(47 \%)$ & 1.00 \\
\hline Diabetes mellitus & $4(24 \%)$ & $4(21 \%)$ & 1.00 \\
\hline Hypertension & $6(35 \%)$ & $9(47 \%)$ & 0.52 \\
\hline Hypercholesterolaemia & $5(29 \%)$ & $3(16 \%)$ & 0.43 \\
\hline \multicolumn{4}{|l|}{ Medication } \\
\hline Aspirin & $17(100 \%)$ & $19(100 \%)$ & 1.00 \\
\hline Clopidogrel & $17(100 \%)$ & $19(100 \%)$ & 1.00 \\
\hline $\begin{array}{l}\text { ACE inhibitor/AT-II receptor } \\
\text { blocker }\end{array}$ & $16(94 \%)$ & $19(100 \%)$ & 0.47 \\
\hline$\beta$-blocker & $14(82 \%)$ & 17 (89\%) & 0.65 \\
\hline Statin & $14(82 \%)$ & $14(74 \%)$ & 0.70 \\
\hline \multicolumn{4}{|l|}{ Lipid profiles } \\
\hline Total cholesterol & \multirow[b]{2}{*}{$108.6(25.6)$} & $195.1(28.4)$ & 0.10 \\
\hline $\begin{array}{l}\text { Low density lipoprotein } \\
\text { cholesterol }\end{array}$ & & $129.3(24.0)$ & $<0.05$ \\
\hline $\begin{array}{l}\text { High density lipoprotein } \\
\text { cholesterol }\end{array}$ & $43.8(11.5)$ & $39.3(9.6)$ & 0.26 \\
\hline Triglyceride & $98.3(38.8)$ & $127.4(51.3)$ & 0.09 \\
\hline hs-CRP & $4.90(5.71)$ & $4.29(4.31)$ & 0.76 \\
\hline
\end{tabular}

Procedural and quantitative angiographic data

Target vessels

LAD/LCX/RCA

Balloon-to-artery ratio

Maximal inflation pressure, atm

Stent size, $\mathrm{mm}$

Stent length, $\mathrm{mm}$

Quantitative angiographic data

Proximal reference vessel

diameter, $\mathrm{mm}$

Minimal luminal diameter, $\mathrm{mm}$

Post-intervention

6-month follow-up

Late luminal loss, mm

$\begin{array}{ccc}6 / 3 / 8 & 11 / 1 / 7 & 0.28 \\ 1.21(0.32) & 1.12(0.15) & 0.43 \\ 13.1(2.1) & 13.9(2.5) & 0.32 \\ 3.13(0.33) & 3.05(0.30) & 0.38 \\ 31.8(14.3) & 29.3(9.8) & 0.54\end{array}$

$3.20(0.33) \quad 3.20(0.40) \quad 0.96$

Results expressed as mean (SD) unless otherwise stated.

hs-CRP, high sensitivity C-reactive protein; LAD, left anterior descending artery; LCX, left circumflex artery; RCA, right coronary artery. 
reference vessel diameter and minimal luminal diameter at postintervention.

\section{Clinical and angiographic variables at 6-month follow-up}

Target vessel revascularisation was performed in one control patient, and no other major adverse cardiovascular events were noted during follow-up. At 6-month follow-up, hs-CRP and LDL cholesterol levels significantly decreased in both groups $(\%$ change in hs-CRP $-65.6 \%$ vs $-95.1 \%$; $\%$ change in LDL cholesterol $-33.5 \%$ vs $-27.9 \%$ for control vs cell infusion group, respectively, $\mathrm{p}<0.05)$. As for angiographic variables at followup, late luminal loss was similarly low in both groups (control 0.30 (SD 0.41) vs cell infusion 0.23 (SD 0.22) $\mathrm{mm}, \mathrm{p}=0.47$ ) and thus the minimal luminal diameter was similar in the two groups (2.64 (SD 0.56) vs 2.61 (SD 0.56) mm, p=0.85).

\section{Changes of plaque areas within the proximal and distal reference segments}

As shown in table 2, the mean lumen area, vessel area, and plaque plus media area of the proximal and distal 5-mm reference segments were similar in the control and cell infusion groups at immediate post-intervention and 6-month follow-up. The interval changes of mean LA, VA, and PMA during 6 months also showed no significant differences between the two groups.

\section{Changes of plaque areas within the stented segments (fig 1)}

Table 3 summarises the quantitative IVUS parameters within the stented segments. The neointimal area at 6 months was similar in the two groups (control 0.3 (SD 0.4 ) $\mathrm{mm}^{2}$ vs cell infusion 0.2 (SD 0.5) $\mathrm{mm}^{2}, \mathrm{p}=0.28$ ). The interval changes of mean lumen area during 6 months showed no significant

Table 2 Intravascular ultrasound results of proximal and distal reference segments

\begin{tabular}{|c|c|c|c|}
\hline & Control & Cell infusion & p Value \\
\hline Proximal reference segment & $\mathrm{n}=9$ & $\mathrm{n}=14$ & \\
\hline \multicolumn{4}{|l|}{ Post-intervention } \\
\hline Mean lumen area, $\mathrm{mm}^{2}$ & $7.9(1.9)$ & $7.7(1.9)$ & 0.69 \\
\hline Mean vessel area, $\mathrm{mm}^{2}$ & $15.2(5.3)$ & $16.3(3.1)$ & 0.14 \\
\hline Mean plaque plus media area, $\mathrm{mm}^{2}$ & $7.2(3.9)$ & $8.6(2.2)$ & 0.09 \\
\hline \multicolumn{4}{|l|}{ 6-month follow-up } \\
\hline Mean lumen area, $\mathrm{mm}^{2}$ & $8.2(1.8)$ & $8.0(1.8)$ & 0.61 \\
\hline Mean vessel area, $\mathrm{mm}^{2}$ & $15.7(4.6)$ & $16.3(2.9)$ & 0.44 \\
\hline $\begin{array}{l}\text { Mean plaque plus media area, } \mathrm{mm}^{2} \\
\text { Interval changes }\end{array}$ & $7.5(3.4)$ & $8.4(1.9)$ & 0.18 \\
\hline$\Delta$ Mean lumen area, $\mathrm{mm}^{2}$ & $0.3(0.8)$ & $0.3(1.1)$ & 0.98 \\
\hline$\Delta$ Mean vessel area, $\mathrm{mm}^{2}$ & $0.5(1.9)$ & $0.1(2.0)$ & 0.61 \\
\hline$\Delta$ Mean plaque plus media area, $\mathrm{mm}^{2}$ & $0.2(1.1)$ & $-0.2(1.5)$ & 0.41 \\
\hline Distal reference segment & $\mathrm{n}=14$ & $\mathrm{n}=16$ & \\
\hline \multicolumn{4}{|l|}{ Post-intervention } \\
\hline Mean lumen area, $\mathrm{mm}^{2}$ & $5.9(2.5)$ & $5.7(1.8)$ & 0.89 \\
\hline Mean vessel area, $\mathrm{mm}^{2}$ & $10.7(4.5)$ & $10.7(3.9)$ & 0.98 \\
\hline Mean plaque plus media area, $\mathrm{mm}^{2}$ & $4.8(2.2)$ & $5.0(2.7)$ & 0.98 \\
\hline \multicolumn{4}{|l|}{ 6-month follow-up } \\
\hline Mean lumen area, $\mathrm{mm}^{2}$ & $5.8(2.3)$ & $5.9(1.8)$ & 0.55 \\
\hline Mean vessel area, $\mathrm{mm}^{2}$ & $10.7(4.3)$ & $11.1(4.0)$ & 0.73 \\
\hline $\begin{array}{l}\text { Mean plaque plus media area, } \mathrm{mm}^{2} \\
\text { Interval changes }\end{array}$ & $4.9(2.4)$ & $5.1(2.7)$ & 0.99 \\
\hline$\Delta$ Mean lumen area, $\mathrm{mm}^{2}$ & $-0.1(0.5)$ & $0.2(0.8)$ & 0.16 \\
\hline$\Delta$ Mean vessel area, $\mathrm{mm}^{2}$ & $0.0(0.5)$ & $0.4(1.1)$ & 0.19 \\
\hline$\Delta$ Mean plaque plus media area, $\mathrm{mm}^{2}$ & $0.1(0.3)$ & $0.1(0.8)$ & 0.60 \\
\hline
\end{tabular}

Results expressed as mean (SD). difference, suggesting no aggravation of neointimal growth with intracoronary stem cell infusion. However, there was a significant increase in vessel area and peri-stent area of stented segment in the cell infusion group compared with the control group. When the patients were divided by the type of DES implanted (table 2), we found that the significant increase in the vessel area and peri-stent area in the cell infusion group was mainly due to the effects of cell infusion in those receiving PES.

\section{DISCUSSION}

This study reports for the first time serial IVUS analysis after intracoronary infusion of PBSCs mobilised by G-CSF in patients with acute myocardial infarction treated by DES implantation. The major findings of this study are as follows: 1) cytokinebased stem cell therapy with intracoronary infusion of mobilised PBSCs did not aggravate in-stent neointimal hyperplasia in the case of DES implantation; 2) intracoronary infusion of PBSCs after cytokine therapy did not adversely affect de novo lesions in the proximal and distal segments of DES; 3) intracoronary stem cell infusion after cytokine therapy showed positive remodelling within the DES segment, especially in patients receiving PES.

\section{Effect of intracoronary infusion of PBSCs on neointimal hyperplasia}

In 2004, we reported that G-CSF was associated with greater late lumen loss and higher restenosis rates after bare metal stent implantation, especially when G-CSF was injected before stent implantation. ${ }^{3}$ In another study, we showed that G-CSFmediated neointimal growth was associated with mobilisation of smooth muscle progenitor cells and inflammation induced by G-CSF. ${ }^{8}$ In this situation, DES was effective in preventing neointimal growth aggravated by G-CSF, while G-CSF facilitated re-endothelialisation of DES. ${ }^{8}$ Based on these findings we conducted the MAGIC Cell-3-DES trial, in which we found that the combination of G-CSF-mobilised stem cell therapy with DES was safe and effective, and that infusion of the cells mobilised by G-CSF did not aggravate in-stent restenosis after DES implantation based on angiographic analysis. ${ }^{7}$ In this IVUS substudy, there was no significant difference in mean area of neointimal hyperplasia analysed by IVUS between the control and the cell infusion group, confirming our previous angiographic findings that the risk of in-stent restenosis was not increased after cytokine-based peripheral blood stem cell therapy with DES implantation.

\section{Effect of intracoronary infusion of PBSCs on de novo atherosclerotic lesions}

Although conflicting data have been reported with regard to the effect of stem cell therapy on de novo atheromatous plaque progression, it has been persistently suggested that the possibility of progression of atherosclerosis after stem cell therapy might be a potential limitation. Several reports demonstrated that transplantation of bone marrow-derived mononuclear cells or spleen cell-derived endothelial progenitor cells induced progression of atherosclerotic plaque in apolipoprotein E knockout mice. ${ }^{56}$ In contrast, atheroprotective effects of bone marrow-derived progenitor cells were proposed by Rauscher et al. ${ }^{9}$ Replenishment of endothelial cells would result in restoration of attenuated endothelial cell function and protective effects against atherosclerosis. Adding to these conflicting results in experimental models, there are few data elucidating changes of de novo atherosclerotic lesions after stem 
Figure 1 Exemplary cases of patients who received sirolimus-eluting $(A)$ and paclitaxel-eluting stents (B). Cell infusion does not aggravate neointimal growth compared with baseline. However, the patient who was given a paclitaxel-eluting stent showed positive peri-stent remodelling at 6-month follow-up.
A

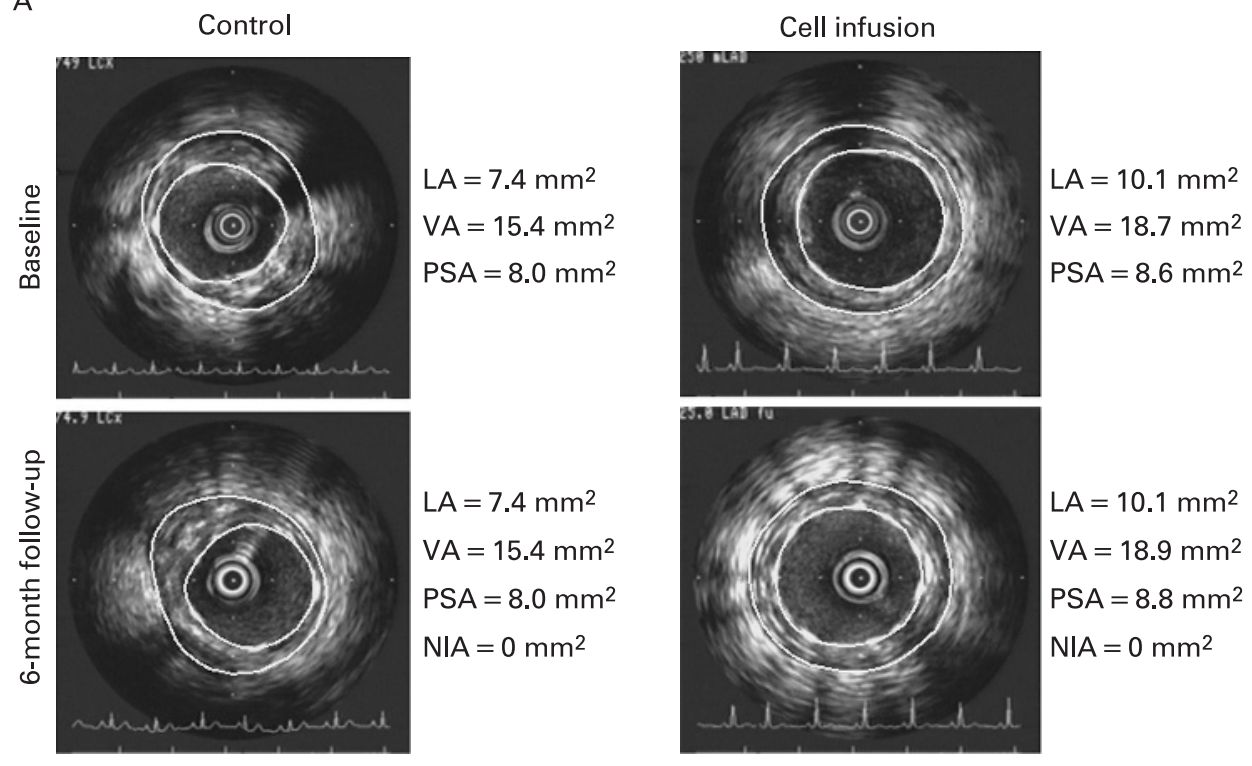

B
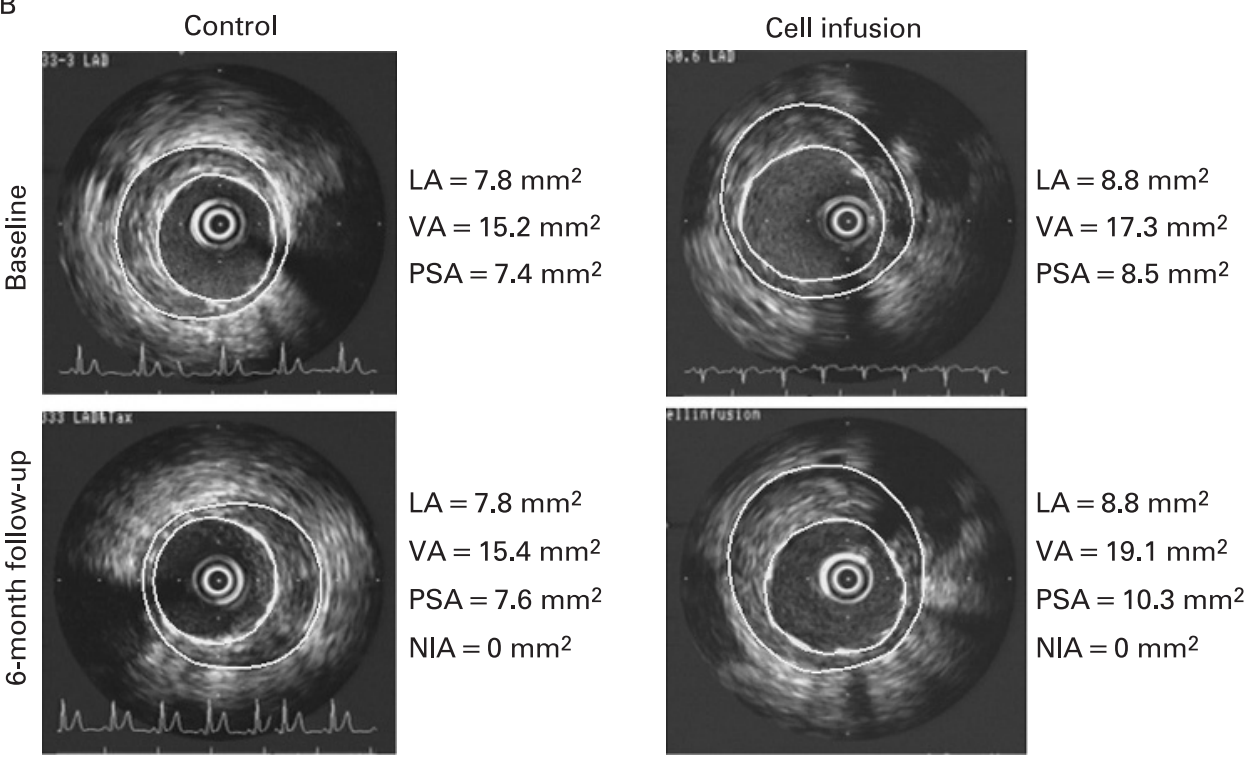

cell therapy, and these were mainly derived from clinical trials using bone marrow-derived stem cells. Cytokine-based PBSC therapy would be different from bone marrow-derived stem cell therapy, because the former has a tendency to increase systemic inflammation, which may be a determining factor for progression of atherosclerosis as well as neointimal growth. Therefore, we evaluated the serial changes of de novo atherosclerotic lesions in reference segments after intracoronary infusion of PBSCs after cytokine therapy by quantitative IVUS analysis to assess the effect of G-CSF-based stem cell therapy on de novo atherosclerotic lesions. Our results showed no significant differences between the control and the cell infusion group in the serial changes of mean lumen area, vessel area and plaque plus media area. To the best of our knowledge, this is the first report on the effect of intracoronary stem cell therapy on the change in human coronary de novo atherosclerosis using IVUS. Our results also support the safety of G-CSF-based stem cell therapy, showing that, at least, it does not aggravate de novo atherosclerosis.

\section{Effect of intracoronary infusion of PBSCs on peri-stent remodelling of stented coronary artery}

An interesting finding from this study was that peri-stent positive remodelling was observed without significant change in lumen area at 6-month follow-up after intracoronary PBSC infusion with DES implantation in patients with AMI, whereas there was no significant interval change in the control group. This result was mainly due to the effect of PBSC infusion in patients implanted with PES rather than SES, suggesting a different biological effect of intracoronary stem cell infusion depending on the type of drug released from the stent.

There are several issues to be investigated to explain this novel finding. The first issue is the reason why stem cell therapy preferentially induced peri-stent tissue growth in stented segments. Tanaka et al ${ }^{10}$ reported that bone marrow cells were preferentially involved in the progression of neointimal hyperplasia only with injury causing endothelial denudation. Therefore, infused stem cells would mainly contribute to tissue growth in the segment subjected to severe injury causing 
Table 3 Intravascular ultrasound results of stented segment

\begin{tabular}{|c|c|c|c|}
\hline & Control & Cell infusion & p Value \\
\hline Total segments & $\mathrm{n}=17$ & $\mathrm{n}=19$ & \\
\hline \multicolumn{4}{|l|}{ Post-intervention } \\
\hline Mean lumen area, $\mathrm{mm}^{2}$ & $6.5(1.7)$ & $6.6(1.4)$ & 0.71 \\
\hline Mean stent area, $\mathrm{mm}^{2}$ & $6.5(1.7)$ & $6.6(1.4)$ & 0.71 \\
\hline Mean vessel area, $\mathrm{mm}^{2}$ & $14.9(3.4)$ & $14.8(2.7)$ & 0.96 \\
\hline Mean peri-stent area, $\mathrm{mm}^{2}$ & $8.4(2.2)$ & $8.2(1.9)$ & 0.82 \\
\hline \multicolumn{4}{|l|}{ 6-month follow-up } \\
\hline Mean lumen area, $\mathrm{mm}^{2}$ & $6.2(1.8)$ & $6.4(1.4)$ & 0.60 \\
\hline Mean stent area, $\mathrm{mm}^{2}$ & $6.5(1.7)$ & $6.6(1.3)$ & 0.68 \\
\hline Mean vessel area, $\mathrm{mm}^{2}$ & $14.8(3.0)$ & $15.5(3.1)$ & 0.55 \\
\hline Mean neointimal area, $\mathrm{mm}^{2}$ & $0.3(0.4)$ & $0.2(0.5)$ & 0.28 \\
\hline Mean peri-stent area, $\mathrm{mm}^{2}$ & $8.3(1.8)$ & $8.9(2.2)$ & 0.63 \\
\hline \multicolumn{4}{|l|}{ Interval changes } \\
\hline$\Delta$ Mean lumen area, $\mathrm{mm}^{2}$ & $-0.3(0.4)$ & $-0.2(0.5)$ & 0.19 \\
\hline$\Delta$ Mean stent area, $\mathrm{mm}^{2}$ & $0.0(0.0)$ & $0.0(0.1)$ & 0.26 \\
\hline$\Delta$ Mean vessel area, $\mathrm{mm}^{2}$ & $-0.1(1.2)$ & $0.7(1.4)$ & 0.042 \\
\hline$\Delta$ Mean neointimal area, $\mathrm{mm}^{2}$ & $0.3(0.4)$ & $0.2(0.5)$ & 0.28 \\
\hline$\Delta$ Mean peri-stent area, $\mathrm{mm}^{2}$ & $-0.1(1.2)$ & $0.7(1.4)$ & 0.05 \\
\hline SES-implanted segments & $\mathrm{n}=10$ & $\mathrm{n}=13$ & \\
\hline \multicolumn{4}{|l|}{ Post-intervention } \\
\hline Mean lumen area, $\mathrm{mm}^{2}$ & $7.1(1.8)$ & $6.4(1.4)$ & 0.31 \\
\hline Mean stent area, $\mathrm{mm}^{2}$ & $7.1(1.8)$ & $6.4(1.4)$ & 0.31 \\
\hline Mean vessel area, $\mathrm{mm}^{2}$ & $16.0(3.3)$ & $14.9(3.0)$ & 0.49 \\
\hline Mean peri-stent area, $\mathrm{mm}^{2}$ & $8.9(2.2)$ & $8.5(2.1)$ & 0.68 \\
\hline \multicolumn{4}{|l|}{ 6-month follow-up } \\
\hline Mean lumen area, $\mathrm{mm}^{2}$ & $7.0(1.8)$ & $6.3(1.4)$ & 0.35 \\
\hline Mean stent area, $\mathrm{mm}^{2}$ & $7.1(1.8)$ & $6.4(1.4)$ & 0.31 \\
\hline Mean vessel area, $\mathrm{mm}^{2}$ & $15.8(2.5)$ & $15.0(3.3)$ & 0.32 \\
\hline Mean neointimal area, $\mathrm{mm}^{2}$ & $0.1(0.1)$ & $0.1(0.1)$ & 0.16 \\
\hline Mean peri-stent area, $\mathrm{mm}^{2}$ & $8.7(1.4)$ & $8.6(2.4)$ & 0.69 \\
\hline \multicolumn{4}{|l|}{ Interval changes } \\
\hline$\Delta$ Mean lumen area, $\mathrm{mm}^{2}$ & $-0.1(0.1)$ & $-0.1(0.1)$ & 0.11 \\
\hline$\Delta$ Mean vessel area, $\mathrm{mm}^{2}$ & $-0.2(1.5)$ & $0.1(1.0)$ & 0.26 \\
\hline$\Delta$ Mean peri-stent area, $\mathrm{mm}^{2}$ & $-0.1(1.5)$ & $0.1(1.0)$ & 0.31 \\
\hline PES-implanted segments & $\mathrm{n}=7$ & $\mathrm{n}=6$ & \\
\hline \multicolumn{4}{|l|}{ Post-intervention } \\
\hline Mean lumen area, $\mathrm{mm}^{2}$ & $5.7(1.0)$ & $7.0(1.2)$ & 0.07 \\
\hline Mean stent area, $\mathrm{mm}^{2}$ & $5.7(1.0)$ & $7.0(1.2)$ & 0.07 \\
\hline Mean vessel area, $\mathrm{mm}^{2}$ & $13.3(3.2)$ & $14.5(2.3)$ & 0.45 \\
\hline Mean peri-stent area, $\mathrm{mm}^{2}$ & $7.6(2.2)$ & $7.5(1.3)$ & 1.00 \\
\hline \multicolumn{4}{|l|}{ 6-month follow-up } \\
\hline Mean lumen area, $\mathrm{mm}^{2}$ & $5.2(1.2)$ & $6.5(1.6)$ & 0.10 \\
\hline Mean stent area, $\mathrm{mm}^{2}$ & $5.7(1.0)$ & $7.0(1.2)$ & 0.07 \\
\hline Mean vessel area, $\mathrm{mm}^{2}$ & $13.4(3.2)$ & $16.6(2.8)$ & 0.10 \\
\hline Mean neointimal area, $\mathrm{mm}^{2}$ & $0.5(0.6)$ & $0.5(0.8)$ & 0.51 \\
\hline Mean peri-stent area, $\mathrm{mm}^{2}$ & $7.7(2.2)$ & $9.6(1.9)$ & 0.28 \\
\hline \multicolumn{4}{|l|}{ Interval changes } \\
\hline$\Delta$ Mean lumen area, $\mathrm{mm}^{2}$ & $-0.5(0.6)$ & $-0.5(0.7)$ & 0.51 \\
\hline$\Delta$ Mean vessel area, $\mathrm{mm}^{2}$ & $0.1(0.6)$ & $2.1(1.2)$ & 0.005 \\
\hline$\Delta$ Mean peri-stent area, $\mathrm{mm}^{2}$ & $0.2(0.6)$ & $2.1(1.2)$ & 0.005 \\
\hline
\end{tabular}

Results expressed as mean (SD).

disruption of the endothelial layer. We also observed that infused stem cells were preferentially localised in injured segments after balloon injury in rabbit iliac artery. ${ }^{8}$ This finding well explained discrepancy in vascular remodelling between stented segments and segments without intervention. In contrast to the segments without intervention, the endothelial layer of stented segments was severely disrupted, leading to infiltration of vascular smooth muscle progenitor cells included in the infused stem cells to participate in tissue growth or vascular remodelling. ${ }^{11}$ Furthermore, considering the delayed endothelial recovery with DES, the relative contribution of stem cells to vascular remodelling can be augmented by DES implantation.

The second and third issues are the reason why stem cell therapy induced peri-stent positive remodelling without intraluminal hyperplasia and how to explain the differential outcomes in the PES and SES groups. We can suggest possible mechanisms to explain these two issues. The difference between sirolimus and paclitaxel in pharmacokinetics and antiproliferative action on smooth muscle lineage cells may be a possible explanation. Sirolimus had relatively concentrationindependent antiproliferative effects on circulating smooth muscle progenitor cells and vascular smooth muscle cells which were cellular components of medial and neointimal hyperplasia (supplementary fig 1). ${ }^{10}{ }^{12}$ In contrast, antiproliferative effects of paclitaxel showed steep concentration-dependent responses. Thus, in the setting of stem cell therapy, the inhibitory action of paclitaxel would decline in the peri-stent medial area, which is relatively distant from the stent strut, whereas sirolimus would exert concentration-independent antiproliferative effects and exert superior inhibition of cell proliferation at the distant peri-stent medial area. This difference between the transmural distribution of sirolimus and paclitaxel may potentiate the differential inhibitory effects of paclitaxel and sirolimus. ${ }^{13}$ However, we cannot distinguish the individual contributions of circulating progenitor cells, resident smooth muscle cells and extracellular matrix or fibrin at the injured site to positive remodelling, so further study is needed to reveal the precise mechanism of positive remodelling observed in our study.

In addition to this experimental evidence, Tanabe et al reported that expansive peri-stent positive remodelling occurred after slow and moderate-releasing PES implantation when comparing postprocedural and follow-up IVUS findings in the TAXUS-II study. ${ }^{14}$ However, these trends were attenuated at longer-term follow-up. ${ }^{15}$ On the basis of this experimental and clinical evidence, there is a possibility that PES may be weaker in preventing positive remodelling in the situation of therapy with G-CSF-mobilised stem cells.

\section{Implication of peri-stent tissue growth or positive remodelling}

The most important point is the impact of peri-stent tissue growth or positive remodelling on clinical outcomes. In the previous studies in which peri-stent remodelling was observed, the relation between peri-stent remodelling and neointimal hyperplasia was conflicting. Hoffmann et al demonstrated a positive correlation between the extent of tissue growth within the stent and surrounding the stent after bare metal stent (BMS) implantation. ${ }^{16}$ In contrast, Nakamura et al demonstrated the distinct trade-off between positive remodelling and in-stent hyperplasia after BMS implantation. ${ }^{17}$ Nakatogawa et al also reported that greater peri-stent positive remodelling after BMS implantation in patients with AMI was associated with less neointimal proliferation and greater luminal gain. ${ }^{18}$ However, in the TAXUS-II trial, the IVUS data showed no significant correlation between the extent of peri-stent remodelling and neointimal hyperplasia in either BMS or DES. ${ }^{14}{ }^{15}$ Our data also showed no significant correlation between the extent of peri-stent hyperplasia and neointimal hyperplasia, and there was no association between the presence of peri-stent hyperplasia and clinical outcomes. However, it is still possible that the different biological effects of SES and PES in the setting of stem cell therapy might influence clinical outcome in the longer term, and therefore we believe that long-term follow-up data in large-scale clinical trials are needed to address the issue 
of clinical significance of peri-stent tissue growth after DES implantation with stem cell therapy.

\section{Limitations}

First, although this IVUS study was planned as a prospective study, it has a small sample size with a considerable rate of drop-out in IVUS evaluation due to the invasive and complex nature of the study. However, characteristics and outcomes of patients enrolled in the IVUS study were very similar to those of patients enrolled in the MAGIC Cell-3-DES study. Second, a higher LDL cholesterol level in the cell infusion group might unfavourably influence vascular remodelling compared with the control group. However, there was no difference in LDL cholesterol between the PES and SES groups, which showed differences in peri-stent positive remodelling. Furthermore, there was no known relationship between LDL cholesterol level and peri-stent remodelling. Third, we evaluated effects of stem cell therapy on vasculature only with relatively short-term follow-up of 6 months. The outcomes should be evaluated with longer-term follow-up.

In conclusion, stem cell therapy with intracoronary infusion of PBSCs mobilised with G-CSF did not aggravate in-stent neointimal hyperplasia after DES implantation or adversely affect de novo lesions of the coronary artery. An interesting finding is that it induced peri-stent tissue growth in the stented segment, especially in patients receiving PES. The clinical implications of this should be further studied.

Acknowledgements: This study was supported by grants from Stem Cell Research Center (SC3150), Innovative Research Institute for Cell Therapy (H S Kim and H J Kang, A062260), and Seoul National University Hospital (04-2005-015-0), Seoul, Korea.

\section{Competing interests: None.}

\section{REFERENCES}

1. Wollert KC, Meyer GP, Lotz J, et al. Intracoronary autologous bone-marrow cell transfer after myocardial infarction: the BOOST randomised controlled clinical trial. Lancet 2004;364:141-8.

2. Schachinger V, Assmus B, Britten MB, et al. Transplantation of progenitor cells and regeneration enhancement in acute myocardial infarction: final one-year results of the TOPCARE-AMI Trial. J Am Coll Cardiol 2004;44:1690-9.
3. Kang HJ, Kim HS, Zhang SY, et al. Effects of intracoronary infusion of peripheral blood stem-cells mobilised with granulocyte-colony stimulating factor on left ventricular systolic function and restenosis after coronary stenting in myocardial infarction: the MAGIC cell randomised clinical trial. Lancet 2004;363:751-6.

4. Bartunek J, Vanderheyden M, Vandekerckhove B, et al. Intracoronary injection of CD133-positive enriched bone marrow progenitor cells promotes cardiac recovery after recent myocardial infarction: feasibility and safety. Circulation 2005;112:117883.

5. Silvestre JS, Gojova A, Brun V, et al. Transplantation of bone marrow-derived mononuclear cells in ischemic apolipoprotein E-knockout mice accelerates atherosclerosis without altering plaque composition. Circulation 2003;108:2839-42.

6. George J, Afek A, Abashidze A, et al. Transfer of endothelial progenitor and bone marrow cells influences atherosclerotic plaque size and composition in apolipoprotein E knockout mice. Arterioscler Thromb Vasc Biol 2005;25:2636-41.

7. Kang HJ, Lee HY, Na SH, et al. Differential effect of intracoronary infusion of mobilized peripheral blood stem cells by granulocyte colony-stimulating factor on left ventricular function and remodeling in patients with acute myocardial infarction versus old myocardial infarction: the MAGIC cell-3-DES randomized controlled trial. Circulation 2006;114(S):I-145-I-151.

8. Cho HJ, Kim TY, Cho HJ, et al. The effect of stem cell mobilization by granulocytecolony stimulating factor on neointimal hyperplasia and endothelial healing after vascular injury with bare-metal versus paclitaxel-eluting stents. J Am Coll Cardiol 2006; 48:366-74.

9. Rauscher FM, Goldschmidt-Clermont PJ, Davis BH, et al. Aging, progenitor cell exhaustion, and atherosclerosis. Circulation 2003;108:457-63.

10. Tanaka K, Sata M, Hirata $Y$, et al. Diverse contribution of bone marrow cells to neointimal hyperplasia after mechanical vascular injuries. Circ Res 2003;93:783-90.

11. Komatsu R, Ueda M, Naruko T, et al. Neointimal tissue response at sites of coronary stenting in humans: macroscopic, histological, and immunohistochemical analyses. Circulation 1998;98:224-33.

12. Schwartz SM. Smooth muscle migration in atherosclerosis and restenosis. J Clin Invest 1997; 100:S87-9.

13. Levin AD, Vukmirovic N, Hwang CW, et al. Specific binding to intracellular proteins determines arterial transport properties for rapamycin and paclitaxel. Proc Natl Acad Sci USA 2004;101:9463-7.

14. Tanabe K, Serruys PW, Degertekin M, et al. Chronic arterial responses to polymercontrolled paclitaxel-eluting stents: comparison with bare metal stents by serial intravascular ultrasound analyses: data from the randomized TAXUS-II trial. Circulation 2004;109:196-200.

15. Aoki J, Colombo A, Dudek D, et al. Peristent remodeling and neointimal suppression 2 years after polymer-based, paclitaxel-eluting stent implantation. Insights from serial intravascular ultrasound analysis in the TAXUS II study. Circulation 2005;112:387683.

16. Hoffmann R, Mintz GS, Popma JJ, et al. Chronic arterial responses to stent implantation: a serial intravascular ultrasound analysis of Palmaz-Schatz stents in native coronary arteries. J Am Coll Cardiol 1996;28:1134-9.

17. Nakamura M, Yock PG, Bonneau HN, et al. Impact of peri-stent remodeling on restenosis: a volumetric intravascular ultrasound study. Circulation 2001;103:2130-2.

18. Nakatogawa T, Hibi K, Furukawa E, et al. Impact of peri-stent remodeling on instent neointimal proliferation in acute myocardial infarction. Am J Cardiol 2004;94:769-71. 